\title{
Nutraceutical Supplementation Based on Colostrum as Osteoporosis Treatment: A Pilot Study
}

\section{Styliani Ziaka1, Tânia Amorim², Maria Vliora3 ${ }^{3}$, Paraskevi Gkiata3 ${ }^{3}$, Konstantinos Mantzios ${ }^{3}$, Georgia Ntina1 ${ }^{1}$, Eirini K. Kydonaki², Vasileios Gkizlis ${ }^{4}$, Yiannis Koutedakis ${ }^{3,5^{*}}$}

\author{
${ }^{1}$ Biomechanical Solutions, Karditsa, Greece \\ ${ }^{2}$ UCIBIO/REQUIMTE, Faculty of Pharmacy, University of Porto, Porto, Portugal \\ ${ }^{3}$ FAME Laboratory, Department of Physical Education and Sport Science, University of Thessaly, Trikala, Greece \\ ${ }^{4}$ Health Center of Mouzaki, Karditsa, Greece \\ ${ }^{5}$ Faculty of Education, Health and Wellbeing, University of Wolverhampton, Walsall, UK \\ Email: info@bme.gr, ffup@ff.up.pt, laboratory@gmail.com,en-quiries@wlv.ac.uk, *y.koutedakis@uth.gr
}

How to cite this paper: Ziaka, S., Amorim, T., Vliora, M., Gkiata, P., Mantzios, K. Ntina, G., Kydonaki, E.K., Gkizlis, V. and Koutedakis, Y. (2021) Nutraceutical Supplementation Based on Colostrum as Osteoporosis Treatment: A Pilot Study. Food and Nutrition Sciences, 12, 659-669. https://doi.org/10.4236/fns.2021.127049

Received: May 27, 2021

Accepted: July 4, 2021

Published: July 7, 2021

Copyright $\odot 2021$ by author(s) and Scientific Research Publishing Inc. This work is licensed under the Creative Commons Attribution International License (CC BY 4.0).

http://creativecommons.org/licenses/by/4.0/

\begin{abstract}
Introduction: Naturally based treatments for osteoporosis are currently limited. The purpose of this investigation was to ascertain whether bovine colostrum supplementation can improve bone health in humans. Methods: In total 63 individuals volunteered in a 4-month supplementation project. They were stratified into three groups: 1) Healthy post-menopausal women ( $\mathrm{n}=$ $24) ; 2)$ Individuals with osteopenia $(\mathrm{n}=25) ; 3)$ People with osteoporosis $(\mathrm{n}=$ 14). Participants of each group were randomly assigned into two experimental sub-groups: a) The bovine colostrum (BC) supplementation $(200 \mathrm{~mL} /$ day; 5 days/week); b) The placebo sub-group. Before and after the 4-month supplementation, blood samples were obtained and bone mineral density (BMD) was measured. Dual-Energy X-ray Absorptiometry (DXA) was performed on three different anatomical sites: lumbar spine (LS), left femur neck (FN), and left forearm (Arm). Bone health markers (bone alkaline phosphatase (BAP), osteocalcin, C-terminal telopeptide (CTX-I), deoxypyridinoline (DPD)) as well as immunological markers (interleukin 6 (IL6) and immunoglobulin E (IgE)), were assessed in blood serum with enzyme immunoassays, at baseline and 4-months after BC supplementation. Results: No significant changes were found in bone densitometry factors ( $p>0.05$ ), for all studied blood parameters and their calculated effect sizes. Conclusions: It is concluded that, as studied herein, BC does not seem to affect human bone health. This pilot study though warrant the need for further research into the efficacy of BC in patients with osteoporosis.
\end{abstract}




\section{Keywords}

Nutraceutical Supplementation, Bone Nutrients, Osteoporosis, Bovine Colostrum, Post-Menopausal Women

\section{Introduction}

Osteoporosis, a Greek term literally meaning "bone with holes", is used to describe a systemic skeletal disorder of low bone mass and bone micro-architectural deterioration, and the accompanying bone fragility [1]. It is defined as a bone density of 2.5 standard deviations below that of a young adult, at one or more anatomical sites [2] [3], and it is the most common reason for a broken bone among elderly individuals; approximately $50 \%$ of post-menopausal women experience at least one bone fracture [4]. Bone fractures in these individuals are clearly associated with increased medical costs [5] and mortality rates [6].

Many risk factors have been linked to osteoporosis, including hormonal elements, the use of certain drugs, inadequate physical activity since childhood, smoking, low intake of calcium and vitamin D, or small body size [7]. Approximately $2 \%$ to $8 \%$ of males and $9 \%$ to $38 \%$ of females in the developed world are affected [8]. Non pharmaceutical methods, such as individualised weightbearing physical exercise and appropriate nutrition [9], as well as pharmacological therapies have been employed to prevent or treat osteoporosis. Bisphosphonates are usually the first choice for osteoporosis treatment [10]. However, although not life threatening, several adverse effects have been reported in relation to the use of such treatments [11]. Therefore, exploring the efficacy of certain nutraceutical supplements to combat osteoporosis, warrants serious scientific attention.

Milk and dairy-product supplementation is widely recommended to avert osteoporosis and subsequent fractures, as selected functional ingredients, such as milk basic protein, casein phosphopeptide, and lactoferrin, have been shown to be beneficial for bone health [12]. Bovine colostrum (BC) is the first nourishment of mammalian neonates containing nutrient-rich, immune, developmental and tissue-repairing factors produced by the mammary glands shortly after birth. Animal studies have shown that colostrum is an important functional substance for bone health [13], as it contains a plurality of nutrients, including immune and nutritional factors [14]. Regarding the latter, for instance lactoferrin-a multifunctional protein which is found in colostrum in high concentrations, has a positive effect on bone formation while reducing the action of osteoclasts [15]. Insulin-like growth factor 1 (IGF-1) and 2 (IGF-2) which enhance the action of osteoblasts are also abundant in bovine colostrum. In addition, bovine colostrum consists of carbohydrates, immunoglobulins and other proteins, nucleotides, enzymes and enzyme inhibitors, lipids, minerals, and vitamins. It has been shown that the levels of vitamin D and vitamin $\mathrm{K} 1$ are significantly higher in colostrum 
compared to normal milk [14].

Based on the aforementioned information we hypothesized that colostrumbased dietary supplements may enhance bone growth and development in humans. Thus, the purpose of this interventional, double-blind, randomized, placebocontrolled pilot study was to investigate whether BC supplementation could positively affect selected serum bone markers.

\section{Materials and Methods}

\subsection{Volunteers}

Eighty-five volunteers were assessed for eligibility. Most of the participants were living in Trikala and all of them in the administrative region of Thessaly, Greece. Inclusion criteria were as follows: postmenopausal women (no menses for at last one year); osteoporosis patients (female): T-score $<-2.5$ at the femoral neck (or other anatomical site); osteopenia patients (female): T-score $<-1.0$ at the femoral neck (or other anatomical site); osteopenia patients (male): T-score < -1.0 at the femoral neck (or other anatomical site); not taking drugs for osteoporosis or have been on a wash-out period for at least one month before starting supplementation; not taking any supplements; no other diseases (diabetes, heart disease, etc.).

Based on the above criteria, 63 (male $\mathrm{n}=9$ ) volunteers were selected with a mean age of $59.8 \pm 8.5 \mathrm{yrs}$ (Table 1 ). Following bone density assessments, the 63 volunteers were allocated (according to their status) to three different groups: a) Healthy postmenopausal women $(\mathrm{n}=24)$; b) People with osteopenia $(\mathrm{n}=$ 25); c) People with osteoporosis $(n=14)$ (Table 1). Written informed consent has been obtained from the patients to participate in the study. The study was conducted in accordance with the Declaration of Helsinki, and the protocol was approved by the Ethics Committee of University of Thessaly, Greece (protocol no: 1298) and registered on the ClinicalTrials.gov (NCT04040010). A flowchart of the methodology used to recruit and assess participants for bone health as well as to allocate them in the different experimental sub-groups is described in Figure 1.

\subsection{Bovine Colostrum (BC) Supplementation}

BC supplement was provided by the Hellenic Dairies S.A. (Trikala, Greece) according to the European Commission Regulation (EC) No 1662/2006 and No $1663 / 2006$ for the production of milk-related products. The weekly supplement consisted of $300 \mathrm{~mL} / \mathrm{L} \mathrm{BC}, 100 \mathrm{~mL} / \mathrm{L}$ vanilla sweetener and $600 \mathrm{~mL} / \mathrm{L}$ lactosefree cow milk.

Within each of the three groups described above, participants were randomized into either the experimental sub-group that received the BC supplement, or the placebo sub-group that received sham supplementation $(900 \mathrm{~mL} / \mathrm{L}$ lactose free cow milk and $100 \mathrm{~mL} / \mathrm{L}$ vanilla sweetener). All participants consumed 200 $\mathrm{mL}$ of the appropriate supplement per day, 5 times per week, for four consecutive 


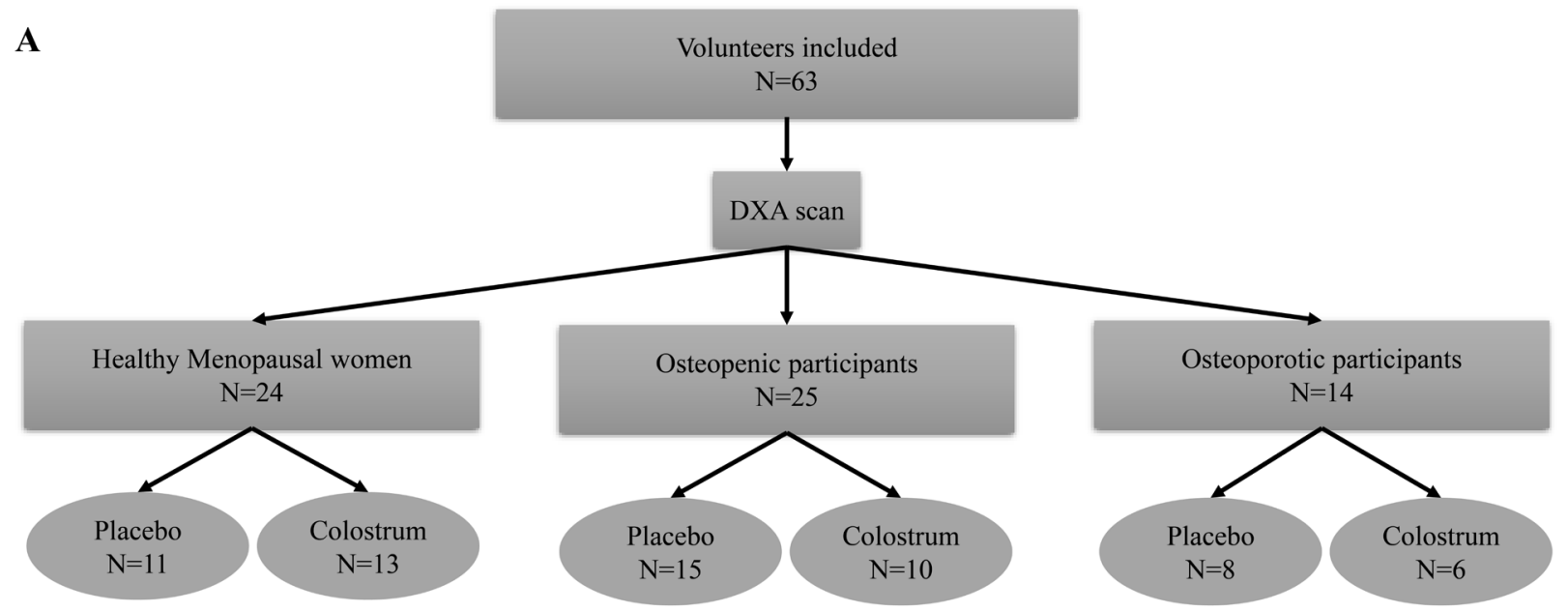

\section{B}

Baseline Measurements (Day 0)

Daily Bovine Colostrum

Blood sampling and DXA

Supplementation

End of experimental protocol (Day 120)

Blood sampling and DXA

Key: DXA = Dual X-ray Absorptiometry.

Figure 1. Flowchart of methodology. (A) Method used to recruit the participants in the study and include them in the appropriate experimental sub-groups. (B) Experimental protocol.

months. Those on medications for osteopenia or osteoporosis, went through a wash-out period of one month before entering the experimental procedure. Bone density measurements and blood samples were obtained from each participant at baseline and at the end of the experimental protocol. The participants that consisted the different experimental sub-groups and the experimental protocol are described in Figure 1.

\subsection{Bone Densitometry}

Bone mineral density (BMD) of the lumbar spine (lumbar vertebrae L1-L4) (LS), femoral neck (FN) and forearm (Arm) was assessed via dual energy X-ray Absorptiometry (DXA) (Lunar Radiation Corporation, Madison, WI). We also calculated T-scores for the same anatomical sites. These data were used to allocate the participants in the three different groups (healthy post-menopausal women, individuals with osteopenia and people with osteoporosis) according to their bone health in order to evaluate the differences before and after the $\mathrm{BC}$ supplementation.

\subsection{Blood Serum Parameters}

Before and after the four-month supplementation, blood samples were obtained from the participants after an $8 \mathrm{~h}$ fasting period, by a certified phlebotomist. Blood samples were allowed to clot at room temperature for $20 \mathrm{~min}$ and serum was separated by centrifugation at $1370 \mathrm{~g}$, for $10 \mathrm{~min}$, at $4^{\circ} \mathrm{C}$. Serum samples 
were stored at $-80^{\circ} \mathrm{C}$ for further analyses.

To identify whether the BC supplement was capable of stimulating immunological responses, interleukin 6 (IL-6) and immunoglobulin $\mathrm{E}$ (IgE) were assessed as markers for allergy, using a Human IL-6 ELISA kit (Boster Inc., China), and an IgE ELISA kit (Immunodiagnostik, Bensheim, Germany), respectively, according to manufacturers' guidelines.

Bone formation markers BAP (bone alkaline phosphatase) and osteocalcin were evaluated using an enzyme immunoassay (EIA) kit (Ostase ${ }^{\circledast}$ BAP, IDS) and an enzyme-linked immunosorbent assay (ELISA) kit (N-MID ${ }^{\oplus}$ Osteocalcin, IDS), respectively. For bone resorption we assessed deoxypyridinoline (DPD) and C-terminal telopeptide of type 1 collagen (CTX-I) before and after the BC supplementation, using a Human DPD ELISA kit (Biotech Co., Wuhan, China) and an ELISA kit (Serum CrossLaps ${ }^{\circledR}$ (CTX-I)) (IDS), respectively. All samples were assessed at least in duplicates.

\subsection{Statistical Analyses}

A Power Analysis using the software $G^{\star}$ Power (90\% power; $0.05 \%$ ) was conducted [16]. To assess any immunological responses within the participants that received BC supplementation, we performed a Paired samples t-test and Wilcoxon signed-ranks test between the baseline and the four-month follow-up. The same analyses were employed for the two allergy markers (IL-6 and IgE). A 2 experimental sub-groups (BC vs placebo) $\times 3$ bone health groups (healthy post-menopausal women, individuals with osteopenia and people with osteoporosis) $\times 2$ time (baseline vs 4 -month follow-up) repeated measures analysis was conducted to evaluate differences in bone densitometry factors and bone markers. Post-hoc tests with Bonferroni's adjustment were performed for multiple comparisons. Analyses were conducted using SPSS 22.0 for Windows (IBM, Armonk, NY, USA) and the level of significance was set at $\mathrm{P}<0.05$.

\section{Results}

Table 1 shows baseline characteristics for all participants (Mean \pm SD).

We compared the values of allergy markers between baseline and four-month supplementation samples. No immunological responses were observed after the

Table 1. Participant's characteristics in the three groups according to bone status

\begin{tabular}{ccccc}
\hline & Total & Normal $(\mathrm{N}=24)$ & Osteopenia $(\mathrm{N}=25)$ & Osteoporosis $(\mathrm{N}=14)$ \\
\cline { 2 - 5 } $\mathrm{N}$ & 63 & $\begin{array}{c}(\mathrm{BC}=11, \\
\text { Placebo }=13)\end{array}$ & $\begin{array}{c}(\mathrm{BC}=15, \\
\text { Placebo }=10)\end{array}$ & $\begin{array}{c}(\mathrm{BC}=8, \\
\text { Placebo }=6)\end{array}$ \\
\hline Age (yrs.) & $59.8 \pm 8.5$ & $55.2 \pm 4.1$ & $62.7 \pm 10.2$ & $62.5 \pm 7.4$ \\
Weight $(\mathrm{kg})$ & $70.9 \pm 12.5$ & $73.2 \pm 11.0$ & $71.3 \pm 13.1$ & $66.3 \pm 13.4$ \\
Height $(\mathrm{cm})$ & $163.2 \pm 7.0$ & $163.0 \pm 6.0$ & $165.6 \pm 8.5$ & $159.5 \pm 3.9$ \\
BMI $\left(\mathrm{kg} / \mathrm{m}^{2}\right)$ & $27.6 \pm 4.6$ & $27.6 \pm 4.5$ & $26.0 \pm 4.2$ & $26.1 \pm 5.2$ \\
\hline
\end{tabular}

Key: $\mathrm{BC}=$ Bovine Colostrum, BMI = Body Mass Index. 
four-month BC supplementation ( $\mathrm{P}>0.05)$. For both IL6 $(29.81 \pm 2.16 \mathrm{pg} / \mathrm{mL} ; 4$ months $=30.8 \pm 2.44 \mathrm{pg} / \mathrm{mL}$ ) and $\mathrm{IgE}$ (baseline $=3.23 \pm 3.9 \mathrm{kU} / \mathrm{l} ; 4$ months $=$ $3.86 \pm 4.5 \mathrm{kU} / \mathrm{l}$ ) level, we did not observe any significant changes (Table 2).

DXA results and effect sizes for differences between baseline and 4-month follow-up measurements for all different groups, are exhibited in Table 3 and Table 4. The experimental sub-groups that received BC supplementation demonstrated no significant results in bone densitometry factors $(\mathrm{P}>0.05)$. A large effect size was observed in the healthy postmenopausal women that were receiving $\mathrm{BC}$ supplementation, for the BMD-Arm $(\mathrm{d}=0.82)$, although there were no statistically significant differences $(\mathrm{P}>0.05)$.

The results for bone health markers are presented in Table 5. Within the experimental groups that received BC supplementation, CTX-I concentration $(\mathrm{P}<$ $0.05)$ was significantly increased in participants with osteoporosis. The calculated effect size was large $d=0.86$, according to the Cohen's criteria.

\section{Discussion}

Although the beneficial effects of milk and dairy products intake on human bone health, with particular emphasis on osteoporosis, have been generally highlighted [17], little is known as to whether the same applies for BC. Therefore, the purpose of this investigation was to ascertain whether BC supplementation

Table 2. Paired samples T-test for allergy markers at baseline and after 4 months of BC supplementation (means $\pm \mathrm{SD}$ ).

\begin{tabular}{ccc}
\hline & Baseline & 4 months \\
\hline IL6 & $29.81 \pm 2.16$ & $30.8 \pm 2.44$ \\
IgE & $3.23 \pm 3.90$ & $3.86 \pm 4.50$ \\
\hline
\end{tabular}

Table 3. Post-hoc comparisons using Bonferroni's adjustment for bone density at the three different anatomical sites (means $\pm \mathrm{SD}$ ).

\begin{tabular}{|c|c|c|c|c|c|c|c|}
\hline & & BC & supplementation & & placebo & & \\
\hline & & Baseline & 4 months & d & Baseline & 4 months & $\mathrm{d}$ \\
\hline \multirow{3}{*}{$\begin{array}{c}\text { BMD_LS } \\
\left(\mathrm{g} / \mathrm{cm}^{2}\right)\end{array}$} & Normal & $1.2 \pm 0.2$ & $1.2 \pm 0.1$ & 0.03 & $1.1 \pm 0.1$ & $1.1 \pm 0.1$ & 0.14 \\
\hline & Osteopenia & $1.0 \pm 0.1$ & $1.0 \pm 0.1$ & 0.10 & $1.0 \pm 0.1$ & $0.8 \pm 0.8$ & 0.36 \\
\hline & Osteporosis & $1.0 \pm 0.1$ & $1.0 \pm 0.1$ & 0.17 & $0.9 \pm 0.1$ & $0.9 \pm 0.1$ & 0.01 \\
\hline \multirow{3}{*}{$\begin{array}{c}\text { BMD_FN } \\
\left(\mathrm{g} / \mathrm{cm}^{2}\right)\end{array}$} & Normal & $0.9 \pm 0.1$ & $0.9 \pm 0.1$ & 0.05 & $0.9 \pm 0.1$ & $0.9 \pm 0.1$ & 0.02 \\
\hline & Osteopenia & $0.9 \pm 0.1$ & $0.9 \pm 0.1$ & 0.25 & $0.9 \pm 0.1$ & $0.8 \pm 0.4^{\mathrm{a}}$ & 0.42 \\
\hline & Osteporosis & $0.8 \pm 0.1$ & $0.8 \pm 0.1$ & 0.11 & $0.8 \pm 0.1$ & $0.8 \pm 0.1$ & 0.11 \\
\hline \multirow{3}{*}{$\begin{array}{c}\text { BMD_Arm } \\
\left(\mathrm{g} / \mathrm{cm}^{2}\right)\end{array}$} & Normal & $0.1 \pm 0.06$ & $0.6 \pm 0.7$ & 0.82 & $0.8 \pm 0.1$ & $0.6 \pm 0.6$ & 0.48 \\
\hline & Osteopenia & $0.8 \pm 0.1$ & $0.8 \pm 0.1$ & 0.17 & $0.9 \pm 0.1$ & $0.7 \pm 0.6$ & 0.45 \\
\hline & Osteporosis & $0.7 \pm 0.2$ & $0.8 \pm 0.1$ & 0.16 & $0.6 \pm 0.1$ & $0.7 \pm 0.1$ & 0.68 \\
\hline
\end{tabular}

Key: LS = lumber spine, FN = femoral neck, Arm = forearm; $a=$ indicates difference from baseline, significant at $\mathrm{P}<0.05 ; \mathrm{d}=$ effect size. 
Table 4. Post-hoc comparisons using Bonferroni's adjustment for bone density/T-scores at the three different anatomical sites (means $\pm \mathrm{SD}$ ).

\begin{tabular}{cccccccc}
\hline & & BC & supplementation & \multicolumn{3}{c}{ placebo } \\
\cline { 3 - 7 } & & Baseline & 4 months & $\mathrm{d}$ & Baseline & 4 months & $\mathrm{d}$ \\
\hline \multirow{2}{*}{ T-score LS } & Normal & $0.5 \pm 1.3$ & $0.5 \pm 1.1$ & 0.01 & $-0.5 \pm 0.6$ & $-0.4 \pm 0.7$ & 0.16 \\
& Osteopenia & $-1.4 \pm 0.7$ & $-1.5 \pm 0.6$ & 0.15 & $-1.4 \pm 0.7$ & $-1.1 \pm 0.8^{\mathrm{a}}$ & 0.40 \\
& Osteporosis & $-1.9 \pm 0.9$ & $-1.8 \pm 0.8$ & 0.16 & $-2.1 \pm 0.7$ & $-2.1 \pm 0.6$ & 0.03 \\
T-score FN & Normal & $-0.3 \pm 0.9$ & $-0.4 \pm 1.0$ & 0.03 & $-0.4 \pm 0.7$ & $-0.4 \pm 0.7$ & 0.00 \\
& Osteopenia & $-1.0 \pm 0.9$ & $-1.1 \pm 0.8$ & 0.16 & $-0.8 \pm 0.9$ & $-0.7 \pm 0.9$ & 0.09 \\
& Osteporosis & $-1.7 \pm 0.7$ & $-1.8 \pm 0.9$ & 0.13 & $-1.5 \pm 0.7$ & $-1.5 \pm 0.5$ & 0.04 \\
T-score Arm & Normal & $-0.2 \pm 0.6$ & $-0.2 \pm 0.7$ & 0.00 & $-0.1 \pm 0.7$ & $-0.3 \pm 0.6$ & 0.23 \\
& Osteopenia & $-1.1 \pm 0.6$ & $-1.0 \pm 0.6$ & 0.17 & $-0.9 \pm 0.7$ & $-1.0 \pm 1.1$ & 0.12 \\
& Osteporosis & $-1.7 \pm 1.9$ & $-1.4 \pm 1.4$ & 0.14 & $-1.9 \pm 3.1$ & $-2.5 \pm 0.7$ & 0.24 \\
\hline
\end{tabular}

Key: $\mathrm{LS}=$ lumber spine, $\mathrm{FN}=$ femoral neck, Arm = forearm; $\mathrm{a}=$ indicates difference from baseline, significant at $\mathrm{P}<0.05 ; \mathrm{d}=$ effect size.

Table 5. Post-hoc comparisons using Bonferroni's adjustment for bone formation and bone resorption marker values at baseline and after 4 months of $\mathrm{BC}$ supplementation (means $\pm \mathrm{SD}$ ).

\begin{tabular}{|c|c|c|c|c|c|c|c|}
\hline & & BC & supplementation & & placebo & & \\
\hline & & Baseline & 4 months & $\mathrm{d}$ & Baseline & 4 months & d \\
\hline \multirow[t]{3}{*}{ BAP (ng/L) } & Normal & $278.8 \pm 62.8$ & $291.4 \pm 76.0$ & 0.17 & $278.7 \pm 78.2$ & $265.6 \pm 100.4$ & 0.14 \\
\hline & Osteopenia & $202.8 \pm 74.1$ & $200.8 \pm 75.8$ & 0.03 & $260.6 \pm 137.1$ & $274.6 \pm 105.7$ & 0.11 \\
\hline & Osteporosis & $239.1 \pm 48.4$ & $219.1 \pm 60.2$ & 0.34 & $332.3 \pm 173.0$ & $223.3 \pm 30.3^{\mathrm{a}}$ & 0.70 \\
\hline \multirow[t]{3}{*}{ Osteocalcin (ng/L) } & Normal & $7.7 \pm 3.9$ & $7.5 \pm 4.9$ & 0.03 & $8.9 \pm 6.4$ & $9.2 \pm 8.9$ & 0.04 \\
\hline & Osteopenia & $10.3 \pm 6.9$ & $10.0 \pm 5.0$ & 0.05 & $13.8 \pm 5.8$ & $13.7 \pm 6.2$ & 0.00 \\
\hline & Osteporosis & $9.2 \pm 5.4$ & $8.3 \pm 4.7$ & 0.16 & $19.8 \pm 4.2$ & $16.3 \pm 5.6$ & 0.57 \\
\hline \multirow[t]{3}{*}{ DPD (ng/L) } & Normal & $56.3 \pm 2.2$ & $59.0 \pm 5.5$ & 0.59 & $59.3 \pm 2.1$ & $58.2 \pm 3.5$ & 0.38 \\
\hline & Osteopenia & $59.1 \pm 5.6$ & $61.8 \pm 4.9$ & 0.48 & $61.1 \pm 4.5$ & $61.0 \pm 4.6$ & 0.02 \\
\hline & Osteporosis & $61.5 \pm 2.1$ & $64.8 \pm 4.9$ & 0.77 & $57.4 \pm 4.3$ & $59.6 \pm 9.4$ & 0.25 \\
\hline \multirow[t]{3}{*}{ CTX-I (ng/L) } & Normal & $4.5 \pm 0.4$ & $4.5 \pm 0.5$ & 0.03 & $4.5 \pm 0.5$ & $4.6 \pm 0.5$ & 0.04 \\
\hline & Osteopenia & $4.7 \pm 0.3$ & $4.6 \pm 0.4$ & 0.03 & $4.1 \pm 0.5$ & $4.4 \pm 0.4$ & 0.00 \\
\hline & Osteporosis & $4.3 \pm 0.5$ & $4.7 \pm 0.3^{\mathrm{a}}$ & 0.16 & $4.4 \pm 0.3$ & $4.7 \pm 0.4^{\mathrm{a}}$ & 0.57 \\
\hline
\end{tabular}

$\mathrm{a}=$ indicates difference from baseline significant at $\mathrm{P}<0.05 ; \mathrm{d}=$ effect size.

can actually improve bone health in humans and can provide a non-pharmacological solution for osteoporosis.

$\mathrm{BC}$ is the first nourishment of all mammalian neonates containing nutrientrich, immune, developmental and tissue-repairing factors. BC supplementation has been shown-inter alia, to improve exercise performance in highly trained cyclists [18], to increase bone-free lean body mass in adult active men and women 
[19], and to attenuate inflammatory indices following a Loughborough Intermittent Shuttle Test in soccer players [20]. Further, BC acidic protein supplementation has shown to increase the bone mineral content and bone mineral density of the femur in in ovariectomized rats [21], while Growth ProteinColostrum supplementation revealed significantly higher mean osteocalcin serum levels in juvenile rats [13].

The present results revealed that although $\mathrm{BC}$ is safe for human consumption, as no immunological responses were detected after the four-month supplementation, it seems to have no effect in any of the studied bone-health parameters. This was rather surprising given the growing evidence that some of its bioactive components, such as lactoferrin, generate anabolic effects on bone health both in vivo and in vitro [22] [23] [24]. BC, as a whole supplementation also induces positive effects on the phenotype of diabetes type I, on the metabolic control of diabetes type II, on some cardiovascular diseases, on certain gastrointestinal diseases and on the immune responses against primary influenza virus [25] [26] [27].

In general, little is known on the effects of $\mathrm{BC}$ on bone health. A recent systematic review which examined bovine whey and colostrum in relation to health benefits in adults, including bone mineral density, found heterogeneous outcomes, high risk of bias and inconsistent findings resulted in inconclusive evidence to substantiate health claims [28]. It is known, however, that aerobic and anaerobic exercise protocols require 6 - 12 months to elicit osteogenetic changes in adults [29], while a rather shorter duration of 3-month exercise intervention is ineffective in initiating bone biomarker response in healthy elderly men [30].

To our knowledge, there are no published data for direct comparisons regarding the duration of $\mathrm{BC}$ supplementation in relation to bone health. It is therefore conceivable to suggest that the four-month $\mathrm{BC}$ supplementation used in our interventional, double-blind, randomized, placebo-controlled study was not long enough to cause measurable differences in the considered parameters.

Keeping the above in mind, it is reasonable to assume that the present study might have been influenced by methodological limitations such as the use of our own BC as a supplement, "directly" from cows that gave birth, and the lack of protein quantification present in our BC. Also, although our sample of patients is well-defined, we acknowledge that future studies should include bigger sample sizes together with fracture histories. Finally, we cannot exclude the possibility that the dose and duration of our $\mathrm{BC}$ supplementation was insufficient to induce bone mass gains.

\section{Conclusion}

Within the limitations of the current pilot study, it is concluded that whole bovine colostrum does not seem to affect bone-health parameters in osteoporotic patients, following a four-month supplementation period. However, nutraceutical products based on bovine colostrum deserve further investigation, with spe- 
cial attention on the duration and dose of supplementation. Future studies should also investigate the possibility of increasing the amount of lactoferrin, a component known to benefit bone health.

\section{Funding}

This work was supported by the MSCA-RISE-Marie Skłodowska-Curie Research and Innovation Staff Exchange (RISE) grant funded by the European Union (grant agreement ID: 778277).

\section{Acknowledgements}

We thank the Hellenic Dairies S.A. (Trikala, Greece) for the kind donation of bovine colostrum. We would also like to acknowledge Katerina Tsilipounidaki from the Department of Microbiology, Medical School, University of Thessaly, Greece for her valuable help in conducting our wet lab experiments.

\section{Conflicts of Interest}

The authors declare no conflicts of interest regarding the publication of this paper.

\section{References}

[1] Amorim, T., Wyon, M., Maia, J., Machado, J.C., Marques, F., Metsios, G.S., Flouris, A.D. and Koutedakis, Y. (2015) Prevalence of Low Bone Mineral Density in Female Dancers. Sports Medicine, 45, 257-268. https://doi.org/10.1007/s40279-014-0268-5

[2] Keen, M.U. and Reddivari, A.K.R. (2020) Osteoporosis in Females. StatPearls Publishing, Treasure Island.

[3] Boyanov, M., Shinkov, A., Psachoulia, E., Intorcia, M. and Petkova, R. (2017) Baseline Characteristics and Changes in Bone Mineral Density T-Scores of Bulgarian Women with Postmenopausal Osteoporosis Receiving Denosumab in Routine Clinical Practice. Drugs in $R \& D, 17,125-132$. https://doi.org/10.1007/s40268-016-0159-3

[4] Reid, I.R. (2020) A Broader Strategy for Osteoporosis Interventions. Nature Reviews Endocrinology, 16, 333-339. https://doi.org/10.1038/s41574-020-0339-7

[5] Kim, E.G., Bae, G., Kwon, H.Y. and Yang, H. (2021) Aging and Direct Medical Costs of Osteoporotic Fractures. Journal of Bone and Mineral Metabolism. https://doi.org/10.1007/s00774-020-01192-0

[6] Jones, L., Singh, S., Edwards, C., Goyal, N. and Singh, I. (2020) Prevalence of Vertebral Fractures in CTPA's in Adults Aged 75 and Older and Their Association with Subsequent Fractures and Mortality. Geriatrics (Basel), 5, 56. https://doi.org/10.3390/geriatrics5030056

[7] Lane, N.E. (2006) Epidemiology, Etiology, and Diagnosis of Osteoporosis. American Journal of Obstetrics and Gynecology, 194, S3-S11. https://doi.org/10.1016/j.ajog.2005.08.047

[8] Wade, S.W., Strader, C., Fitzpatrick, L.A., Anthony, M.S. and O’Malley, C.D. (2014) Estimating Prevalence of Osteoporosis: Examples from Industrialized Countries. Archives of Osteoporosis, 9, 182. https://doi.org/10.1007/s11657-014-0182-3 
[9] Amorim, T., Koutedakis, Y., Nevill, A., Wyon, M., Maia, J., Machado, J.C., Marques, F., Metsios, G.S., Flouris, A.D., Adubeiro, N., Nogueira, L. and Dimitriou, L. (2017) Bone Mineral Density in Vocational and Professional Ballet Dancers. Osteoporosis International, 28, 2903-2912. https://doi.org/10.1007/s00198-017-4130-0

[10] Wells, G., Cranney, A., Peterson, J., Boucher, M., Shea, B., Robinson, V., Coyle, D. and Tugwell, P. (2008) Risedronate for the Primary and Secondary Prevention of Osteoporotic Fractures in Postmenopausal Women. Cochrane Database of Systematic Reviews, No. 1, CD004523. https://doi.org/10.1002/14651858.CD004523.pub3

[11] Wysowski, D.K. and Chang, J.T. (2005) Alendronate and Risedronate: Reports of Severe Bone, Joint, and Muscle Pain. Archives of Internal Medicine, 165, 346-347. https://doi.org/10.1001/archinte.165.3.350

[12] Van den Heuvel, E. and Steijns, J. (2018) Dairy Products and Bone Health: How Strong Is the Scientific Evidence? Nutrition Research Reviews, 31, 164-178. https://doi.org/10.1017/S095442241800001X

[13] Lee, J., Kwon, S.H., Kim, H.M., Fahey, S.N., Knighton, D.R. and Sansom, A. (2008) Effect of a Growth Protein-Colostrum Fraction on Bone Development in Juvenile Rats. Bioscience, Biotechnology, and Biochemistry, 72, 1-6. https://doi.org/10.1271/bbb.60695

[14] McGrath, B.A., Fox, P.F., McSweeney, P.L.H. and Kelly, A.L. (2016) Composition and Properties of Bovine Colostrum: A Review. Dairy Science \& Technology, 96, 133-158. https://doi.org/10.1007/s13594-015-0258-x

[15] Yang, Z., Jiang, R., Chen, Q., Wang, J., Duan, Y., Pang, X., Jiang, S., Bi, Y., Zhang, H., Lönnerdal, B., Lai, J. and Yin, S. (2018) Concentration of Lactoferrin in Human Milk and Its Variation during Lactation in Different Chinese Populations. $\mathrm{Nu}$ trients, 10, 1235. https://doi.org/10.3390/nu10091235

[16] Faul, F., Erdfelder, E., Buchner, A. and Lang, A.G. (2009) Statistical Power Analyses Using $G^{*}$ Power 3.1: Tests for Correlation and Regression Analyses. Behavior Research Methods, 41 1149-1160. https://doi.org/10.3758/BRM.41.4.1149

[17] Caroli, A., Poli, A., Ricotta, D., Banfi, G. and Cocchi, D. (2011) Invited Review: Dairy Intake and Bone Health: A Viewpoint from the State of the Art. Journal of Dairy Science, 94, 5249-5262. https://doi.org/10.3168/jds.2011-4578

[18] Shing, C.M., Jenkins, D.G., Stevenson, L. and Coombes, J.S. (2006) The Influence of Bovine Colostrum Supplementation on Exercise Performance in Highly Trained Cyclists. British Journal of Sports Medicine, 40, 797-801. https://doi.org/10.1136/bjsm.2006.027946

[19] Antonio, J., Sanders, M.S. and Van Gammeren, D. (2001) The Effects of Bovine Colostrum Supplementation on Body Composition and Exercise Performance in Active Men and Women. Nutrition, 17, 243-247. https://doi.org/10.1016/S0899-9007(00)00552-9

[20] Kotsis, Y., Mikellidi, A., Aresti, C., Persia, E., Sotiropoulos, A., Panagiotakos, D.B., Antonopoulou, S. and Nomikos, T. (2018) A Low-Dose, 6-Week Bovine Colostrum Supplementation Maintains Performance and Attenuates Inflammatory Indices Following a Loughborough Intermittent Shuttle Test in Soccer Players. European Journal of Nutrition, 57, 1181-1195. https://doi.org/10.1007/s00394-017-1401-7

[21] Du, M., Xu, W., Yi, H., Han, X., Wang, C. and Zhang, L. (2011) Protective Effects of Bovine Colostrum Acid Proteins on Bone Loss of Ovariec-Tomized Rats and the Ingredients Identification. Molecular Nutrition \& Food Research, 55, 220-228. https://doi.org/10.1002/mnfr.200900593

[22] Wang, X.Y., Guo, H.Y., Zhang, W., Wen, P.C., Zhang, H., Guo, Z.R. and Ren, F.Z. 
(2013) Effect of Iron Saturation Level of Lactoferrin on Osteogenic Activity in Vitro and in Vivo. Journal of Dairy Science, 96, 33-39. https://doi.org/10.3168/jds.2012-5692

[23] Cornish, J., Callon, K.E., Naot, D., Palmano, K.P., Banovic, T., Bava, U., Watson, M., Lin, J.M., Tong, P.C., Chen, Q., Chan, V.A., Reid, H.E., Fazzalari, N., Baker, H.M., Baker, E.N., Haggarty, N.W., Grey, A.B. and Reid, I.R. (2004) Lactoferrin Is a Potent Regulator of Bone Cell Activity and Increases Bone Formation in Vivo. Endocrinology, 145, 4366-4374. https://doi.org/10.1210/en.2003-1307

[24] Lorget, F., Clough, J., Oliveira, M., Daury, M.C., Sabokbar, A. and Offord, E. (2002) Lactoferrin Reduces in Vitro Osteoclast Differentiation and Resorbing Activity. Biochemical and Biophysical Research Communications, 296, 261-266.

https://doi.org/10.1016/S0006-291X(02)00849-5

[25] Bagwe, S., Tharappel, L.J., Kaur, G. and Buttar, H.S. (2015) Bovine Colostrum: An Emerging Nutraceutical. Journal of Complementary and Integrative Medicine, 12, 175-185. https://doi.org/10.1515/jcim-2014-0039

[26] Rathe, M., Müller, K., Sangild, P.T. and Husby, S. (2014) Clinical Applications of Bovine Colostrum Therapy: A Systematic Review. Nutrition Reviews, 72, 237-254. https://doi.org/10.1111/nure.12089

[27] Bagwe-Parab, S., Yadav, P., Kaur, G., Tuli, H.S. and Buttar, H.S. (2020) Therapeutic Applications of Human and Bovine Colostrum in the Treatment of Gastrointestinal Diseases and Distinctive Cancer Types: The Current Evidence. Frontiers in Pharmacology, 11, Article ID: 01100. https://doi.org/10.3389/fphar.2020.01100

[28] Blair, M., Kellow, N.J., Dordevic, A.L., Evans, S., Caissutti, J. and McCaffrey, T.A. (2020) Health Benefits of Whey or Colostrum Supplementation in Adults $\geq 35$ Years, a Systematic Review. Nutrients, 12, 299. https://doi.org/10.3390/nu12020299

[29] Benedetti, M.G., Furlini, G., Zati, A. and Letizia Mauro, G. (2018) The Effectiveness of Physical Exercise on Bone Density in Osteoporotic Patients. BioMed Research International, 2018, Article ID: 4840531. https://doi.org/10.1155/2018/4840531

[30] Rantalainen, T., Hoffrén, M., Linnamo, V., Heinonen, A., Komi, P.V., Avela, J. and Nindl, B.C. (2011) Three-Month Bilateral Hopping Intervention Is Ineffective in Initiating Bone Biomarker Response in Healthy Elderly Men. European Journal of Applied Physiology, 111, 2155-2162. https://doi.org/10.1007/s00421-011-1849-8 